\title{
Experimental and Theoretical Analysis of Permeability Characteristics of Sandstone under Loading and Unloading
}

\author{
Xinrong Liu ${ }^{1,2}$, Jun Liu ${ }^{1,2, *}$, Ninghui Liang ${ }^{1,2}$, Chunmei He ${ }^{1,2}$, Zuliang Zhong ${ }^{1,2}$ and Bin Zeng ${ }^{3}$ \\ ${ }^{1}$ College of Civil Engineering, Chongqing University, Chongqing 400045, China \\ ${ }^{2}$ Key Laboratory of New Technology for Construction of Cities in Mountain Area (Chongqing University), Ministry of Education, \\ Chongqing 400030, China \\ ${ }^{3}$ School of Civil, Environmental and Mining Engineering, The University of Western Australia, Crawley; WA; 6009, Australia
}

Received 19 June 2016; Accepted 15 October 2016

\begin{abstract}
Permeability variations in sandstone make the Three Gorges Reservoir Region (TGRR) vulnerable to frequent landslide disasters in the sandstone slope. In order to characterize the effects of water level variation and excavation unloading on permeability of sandstone in the TGRR, weathered sandstone samples were selected for permeability characteristics tests in three different ways under loading and unloading. The permeability variation of sandstone under different confining and pore water pressures was studied. A concept called unloading quantity of the effective confining pressure (UQECP), $\xi$, was proposed, and its effect on permeability characteristics of sandstone was studied. Results show that the permeability greatly changes at the loading-unloading cycle with the confining pressure of $110 \mathrm{kPa}-300 \mathrm{kPa}$, whereas it tends to be smaller under the confining pressure of $300 \mathrm{kPa}-800 \mathrm{kPa}$. When the UQECP is $60 \%-85 \%$, the permeability is approximately twice the initial permeability. The permeability ratio rapidly increases and the mutability of the permeability manifests when the UQECP is larger than $85 \%$. When $\xi$ is larger than $85 \%$, special attention should be given to supporting the sandstone slope to prevent future landslides. In addition, the cyclic loading and unloading pore water pressure test reveals a preferable linear relation between the permeability and the pore water pressure. This research provides references for studies on the permeability characteristics of sandstone in the TGRR.
\end{abstract}

Keywords: Three Gorges Reservoir Region (TGRR), sandstone, loading and unloading, permeability characteristics, unloading quantity of the effective confining pressure (UQECP)

\section{Introduction}

A reservoir area is vulnerable to frequently occurring landslide hazards, especially in the vast mountainous areas from the Three Gorges Dam to Chongqing Municipality [15]. Both sides of the $600 \mathrm{~km}$ riverbanks suffered the severest landslide hazards in China. The reservoir bank of the Three Gorges Reservoir Region (TGRR) stores water of up to 175 $\mathrm{m}$ for approximately two to four months a year and as low as $145 \mathrm{~m}$ for five months a year. The water level descends from $175 \mathrm{~m}$ to $145 \mathrm{~m}$ from May to June and rises from $145 \mathrm{~m}$ to $175 \mathrm{~m}$ in October, Such a significant difference in water levels can significantly change the bank slope in the reservoir area [6-7]. Numerous sandstone slopes are also present in the TGRR, which can cause loading and unloading effects on fractured sandstone during engineering activities, such as impoundment and drainage. Meanwhile, changes in the impounded level of the TGRR from season to season greatly affect the seepage field of fractured sandstone in reservoir bank slopes. Most failures of sandstone slopes are generally due to the seepage of underground water into fractured sandstone. These conditions all greatly affect the stability of sandstone slopes in the reservoir area. Therefore, studying the permeability characteristics of fractured sandstone under loading and unloading conditions in the

*E-mail address: 517694008@qq.com

ISSN: 1791-2377 @ 2016 Eastern Macedonia and Thrace Institute of Technology. All rights reserved. x reservoir area is important.

The unloading of rock mass in reservoir bank slopes in the TGRR is usually due to engineering excavation and a decrease in reservoir level. Weathered sandstone samples were analyzed using slope for permeability evolution tests in three different loading-unloading cycles. This process was performed to determine the effects of varying water levels and excavation-induced unloading on the permeability of fractured sandstone in the TGRR.

\section{State of the art}

All rock masses in engineering are under certain stress, and several studies have been conducted on the topic of permeability of rock mass under stress. By using a discrete element method, Baghbanan and Jing [8] developed a new nonlinear algorithm based on the correlation between the aperture and length to predict the normal stress-normal displacement behaviors of fractures. However, the study did not include the permeability of rock mass in unloading conditions. He et al. [9] used composite element method to study the stress-dependent permeability tensor for fractured rock materials. The research was conducted by inputting any in situ stress state into the database based on artificial neural network, which would result in the predicted permeability tensor. Zhao et al. [10] used numerical simulation method to analyze the permeability of fractured rock materials under 
stresses and its effects on solute transport, propagating, and bending fractures. However, the study did not include permeability under cyclic loading and unloading. Yin et al. [11] conducted cyclic loading and unloading experiments on raw coal to analyze their mechanical properties and permeability and porosity changes with stresses. Although the study did not analyze water permeability under cyclic loading, it showed that the permeability and porosity partly decreased permanently during loading. The permeability of clay-rich sandstones [12] and Wilcox shale [13] were studied using the effective stress principle, and a relationship among permeability, pore pressure, and the confining pressure was established. However, no analysis was conducted on the effect of stress on the permeability under an unloading state. Sun et al. [14] studied underground oil storage caverns and suggested the importance of anisotropy in the permeability of fractured rock mass. Zhang et al. [15] used a two-dimensional distinct element code to study the anisotropy in permeability. Although extensive research has been conducted on the permeability of rock mass [16-18], these studies mainly focused on permeability under loading condition. However, numerous unloading situations occur in actual engineering, such as slope excavation and tunnel excavation. Therefore, the permeability characteristics of rock mass under loading and unloading, especially under the unloading condition, were studied in this paper

The remainder of this paper is organized as follows: Section 3 describes the materials and methods used in the permeability characteristics tests of sandstone in the TGRR area. Section 4 analyzes the results of the change in permeability of sandstone. Section 5 establishes the relationship between permeability ratio and the unloading quantity of the effective confining pressure (UQECP). Section 6 summarizes the conclusions.

\section{Methodology}

\subsection{Test instruments and principles}

The triaxial rheometer used in this experiment is developed by the University of Science and Technology in Lille, France, and manufactured by French Top Industrie Company (Figure 1). The triaxial rheometer can spontaneously exert the confining pressure, the deviatoric stress, and the pore water pressure with corresponding maximum values of 60,300 , and $60 \mathrm{MPa}$, respectively. Axial and hoop strains can be measured at the same time. Rock permeability can be obtained through calculation formulas.

Two types of permeability measurement methods for rock samples mainly exist: steady seepage method and transient pressure pulse method; this experiment uses the latter. The basic principle is that containers at the inlet and outlet are connected by the cylinder rock sample, and an initial fluid pressure $p_{0}$ is exerted to achieve balance between the pressure in the containers and the pore pressure within the rock sample. Then, the fluid pressure at the outlet is kept constant, and a pressure increment, $\Delta p$, is transiently exerted at the inlet side. This approach produces a pore pressure gradient between the inlet and outlet, which will allow the fluid to flow into the rock sample. Permeability can be calculated by recording the pressure balance process, and the corresponding formulas are as follows:

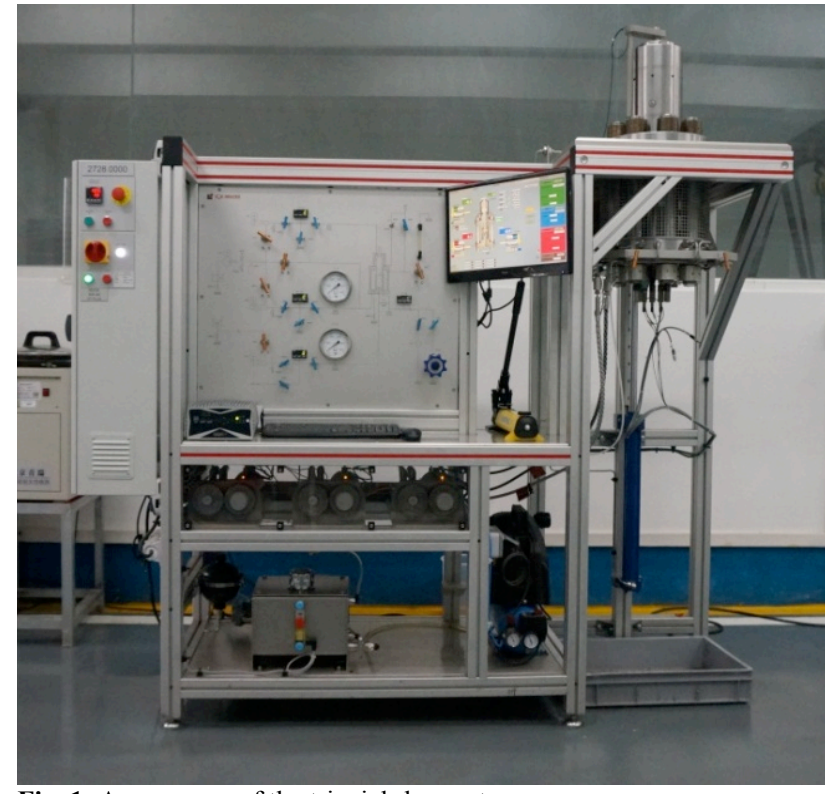

Fig. 1. Appearance of the triaxial rheometer

$$
\begin{aligned}
& p_{\mathrm{u}}-p_{\mathrm{f}}=\Delta p \frac{V_{\mathrm{d}}}{V_{\mathrm{u}}+V_{\mathrm{d}}} e^{-\theta t} \\
& \theta=\frac{k A}{\mu C_{\mathrm{f}} l}\left(\frac{1}{V_{\mathrm{u}}}+\frac{1}{V_{\mathrm{d}}}\right)
\end{aligned}
$$

where $p_{\mathrm{u}}$ is the inlet pressure (MPa); $p_{\mathrm{f}}$ is the fluid pressure when balanced $(\mathrm{MPa}) ; \Delta p$ is the transient pressure increment in the inlet containers $(\mathrm{MPa}) ; V_{\mathrm{u}}$ and $V_{\mathrm{d}}$ are volumes of inlet and outlet containers, respectively $(\mathrm{mL}) ; \mu$ is the fluid viscosity $(\mathrm{Pa} \cdot \mathrm{s})$, and water viscosity at room temperature is $1.005 \times 10^{-3} \mathrm{~Pa} \cdot \mathrm{s}$; $C_{\mathrm{f}}$ is the coefficient of fluid compressibility $\left(\mathrm{MPa}^{-1}\right)$, and the coefficient of water compressibility at room temperature is $4.5 \times 10^{-4} \mathrm{MPa}^{-1} ; k$ is the sample permeability $\left(\mathrm{m}^{2}\right) ; A$ is the cross section area $\left(\mathrm{mm}^{2}\right)$, and $l$ is the sample length $(\mathrm{mm})$.

\subsection{Sample preparation}

Rock samples were collected from a rock slope in the TGRR, which are medium-weathered sandstones of the Middle Jurassic Shaximiao formation. Test pieces are processed to be cylindrical with a height-diameter ratio of 2:1 (diameter $D=50 \mathrm{~mm}$ and height $H=100 \mathrm{~mm}$ ). These pieces are then classified into three groups of $\mathrm{A}, \mathrm{B}$, and $\mathrm{C}$ according to the test scheme, which will be conducted three times. The test parameters and numbers of the typical rock samples are shown in Table 1. Rock samples for all the test schemes underwent $24 \mathrm{~h}$ of vacuum saturation.

\subsection{Test schemes}

In the experiment, the fractured sandstone is obtained by uniaxial compression test on the intact sandstone. Normally, if shear fracture did not link up with the two ends of the sandstone sample, then the permeability of the sandstone sample is the same as that of the intact sandstone. In this paper, however, the fractured sandstone refers to the shear fracture that aligns with the two ends of the sandstone sample. Part of the shear fracture sandstone sample is shown in Figure 2.

Table 1. Test parameters and numbers 


\begin{tabular}{c|c|c|c|c}
\hline Test Sample Number & $\begin{array}{c}\text { Height } \\
/ \mathbf{m m}\end{array}$ & $\begin{array}{c}\text { Diameter } \\
/ \mathbf{m m}\end{array}$ & $\begin{array}{c}\text { Density } \\
/\left(\mathbf{g} \cdot \mathbf{c m}^{-3} \mathbf{)}\right.\end{array}$ & $\begin{array}{c}\text { Porosity } \\
/ \%\end{array}$ \\
\hline A1-1 & 100.23 & 50.10 & 2.265 & 2.64 \\
A2-3 & 100.48 & 50.12 & 2.258 & 2.53 \\
B1-2 & 99.78 & 50.35 & 2.261 & 2.46 \\
B2-2 & 100.12 & 50.26 & 2.254 & 2.63 \\
B3-1 & 100.78 & 50.05 & 2.258 & 2.65 \\
C1-1 & 100.39 & 49.95 & 2.263 & 2.58 \\
C2-3 & 100.56 & 49.98 & 2.259 & 2.56 \\
\hline
\end{tabular}
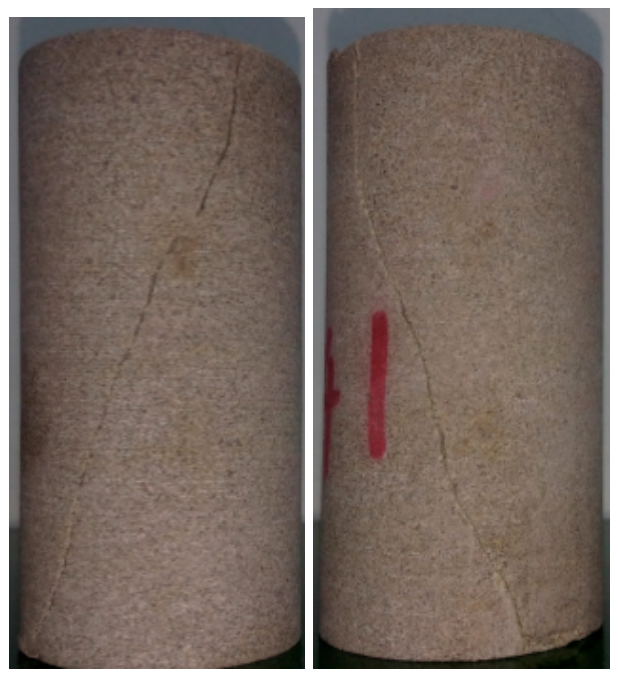

Fig. 2. Part of the shear fracture sandstone sample

Three test schemes are used to test the permeability of sandstone samples from the TGRR.

The first one, Case study A, simulated the engineering excavation of the reservoir bank slope at a certain reservoir water level with a constant pore water pressure of $100 \mathrm{kPa}$ and a cyclic loading and unloading of confining pressure. The test was conducted with eight loading and unloading points at $110,200,300,400,500,600,700$, and $800 \mathrm{kPa}$. The loading increased from $110 \mathrm{kPa}$ to $800 \mathrm{kPa}$ step by step, and later, the unloading was gradually decreased from $800 \mathrm{kPa}$ to $110 \mathrm{kPa}$ (the pore water pressure is lower than the confining pressure to prevent the water from permeating into the hydraulic oil). After each level of confining pressure is stable, permeability was calculated according to Eq. (1). Fractured sandstone samples and intact sandstone samples were then compared.

The second type, Case study B, simulated the potential landslide unloading process of fractured sandstone slopes on the reservoir bank caused by underground water seepage, engineering excavation, or others. The test was conducted under different impoundment conditions with a constant pore water pressure and the confining pressure gradually unloaded. In this situation, the confining pressure of fractured sandstone sample should be first loaded to $800 \mathrm{kPa}$ It is then gradually loaded with 100,200 , and $300 \mathrm{kPa}$ of pore water pressure, which was kept constant as the confining pressure of $100 \mathrm{kPa}$ was unloaded at each level. When the confining pressure was $10 \mathrm{kPa}$ higher than the pore water pressure, it was gradually unloaded to 110,210 , and $310 \mathrm{kPa}$.
The third type, Case study $\mathrm{C}$, simulated the rise and fall of the reservoir water level. The unloading of the fractured sandstone due to underground water was simulated by unloading the confining pressure to a certain value and then keeping this confining pressure constant while gradually loading and unloading the pore water pressure. First, the confining pressure of fractured sandstone samples was loaded to $800 \mathrm{kPa} ; 100 \mathrm{kPa}$ of pore water pressure was first loaded and kept constant; $25 \%(600 \mathrm{kPa})$ of the confining pressure was then unloaded, followed by $50 \%(400 \mathrm{kPa})$ of the confining pressure, and the confining pressure unloading amount was kept constant. With changes in the pore water pressure level for cyclic loading and unloading, the test was designed with three loading and unloading points at 100, 200, and $300 \mathrm{kPa}$. In the experiment, gradual loading was performed from $100 \mathrm{kPa}$ to $300 \mathrm{kPa}$ and then unloading was performed from $300 \mathrm{kPa}$ to $100 \mathrm{kPa}$. This process was repeated twice after each level of loading and unloading.

\section{Result Analysis and Discussion}

\subsection{Case study A}

Figures 3(a) and 3(b) depict the relationship curve between permeability and the confining pressure during loading and unloading on sandstone sample A1-1 (fractured sandstone sample) and A2-3 (intact sandstone sample), respectively.

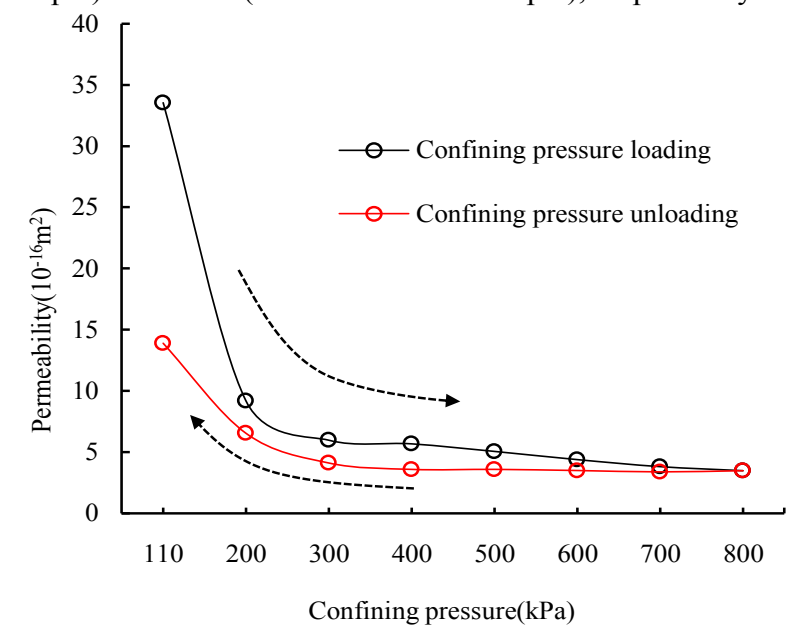

(a) Sandstone sample A1-1

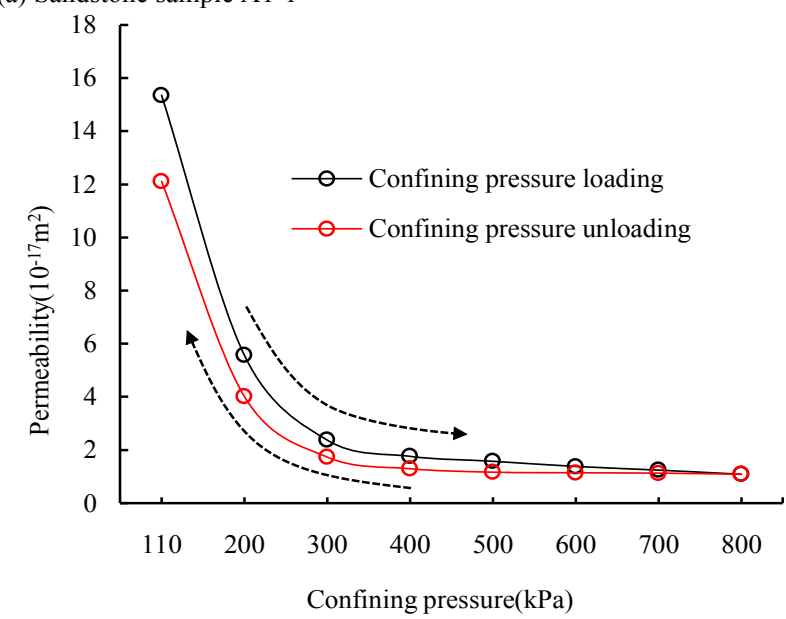

(b) Sandstone sample A2-3

Fig. 3. Curves of relations between permeability and confining pressure 
The following conclusions can be made from Fig. 3:

(1) The permeability of the intact sandstone and the fractured sandstone changed significantly when the confining pressure was loaded from $110 \mathrm{kPa}$ to $300 \mathrm{kPa}$, whereas the permeability of both sandstones decreased to one-seventh and one-fourth, respectively. When confining pressure ranging from $300 \mathrm{kPa}$ to $800 \mathrm{kPa}$ was loaded, the permeability barely changed and gradually became moderate because the increase of confining pressure results in a narrow fracture width and a tight fracture surface bite, thereby resulting in a sharp decline in permeability. When the confining pressure continues to increase, the bite of fracture surface particles becomes balanced; thus, the change of permeability is minimal. This finding indicates that supporting reservoir bank slopes in the TGRR is necessary as it can greatly deceases permeability and thereby effectively control the potential damage to sandstone slopes in the reservoir area.

(2) During loading and unloading of the confining pressure, the recovery degree of permeability of the intact sandstone is higher than that of the fractured sandstone. When $110 \mathrm{kPa}$ confining pressure is unloaded, the permeability of the intact sandstone and the fractured sandstone is $78.9 \%$ and $41.4 \%$, respectively. This result indicates that the unrecoverable plastic deformation in the fractured sandstone is larger, and the hysteresis of its permeability is more observable. This finding suggests that the sandstone slope with relatively developed fractures in the TGRR has comparatively less permeability recovery after undergoing various engineering geological processes. Thus, support is needed for slope stability.

(3) Although trends of permeability of the intact sandstone and fractured sandstone are similar to the process of confining pressure loading and unloading, the permeability of the intact sandstone varies between $10^{-16} \mathrm{~m}^{2}$ and $10^{-17} \mathrm{~m}^{2}$. Meanwhile, the fractured sandstone is approximately 20 times that of the intact sandstone under the same confining pressure. Therefore, the permeability characteristics of sandstone slope are affected by the fractured sandstone in the TGRR.

According to the analysis, the sandstone permeability is closely related to the confining pressure. With the loading and unloading of the confining pressure, the change in the permeability of the sandstone is assumed to be continuous. When the data in Figures 3(a) and 3(b) are fitted, an expression can be obtained as follows:

$k=a+k_{0} /\left[1+\left(\sigma_{3} / b\right)^{t}\right]$

where $k_{0}$ is the initial permeability $\left(\mathrm{m}^{2}\right) ; \sigma_{3}$ is the confining pressure of the test sample $(\mathrm{kPa})$; and $a, b$, and $t$ are regression coefficients. Fitting curves are shown in Figures 4(a) and 4(b), and all regression parameters and $\mathrm{R}^{2}$ are shown in Table 2. Test results considerably fit the fitting formula. Therefore, the permeability mutation area can be predicted based on the data from field measurement, with particular significance for engineering.

\subsection{Case study B}

The permeability change law under different pore water pressures is analyzed, and this law has an effect on the confining pressure. According to research results on the principle of effective stress [12-13,19], the confining pressure on the rock skeleton particle can be expressed as the effective confining pressure, namely,

$$
P_{e f f}=P_{c}-\alpha P_{f}
$$

where $P_{\text {eff }}$ is the effective confining pressure; $P_{c}$ is the confining pressure in the pressure chamber; $P_{f}$ is the pore water pressure; and $\alpha$ is the effective stress coefficient, which is determined by the following formula:

$\alpha=1-K / K_{s}$

where $K$ and $K_{s}$ are the bulk modulus of the rock mass solid particles and of the skeleton, respectively. For most materials, the compressibility of the skeleton is much smaller than that of the particle itself, i.e., $K \ll K_{s}$. Therefore, this study takes $\alpha=1$ for convenience.

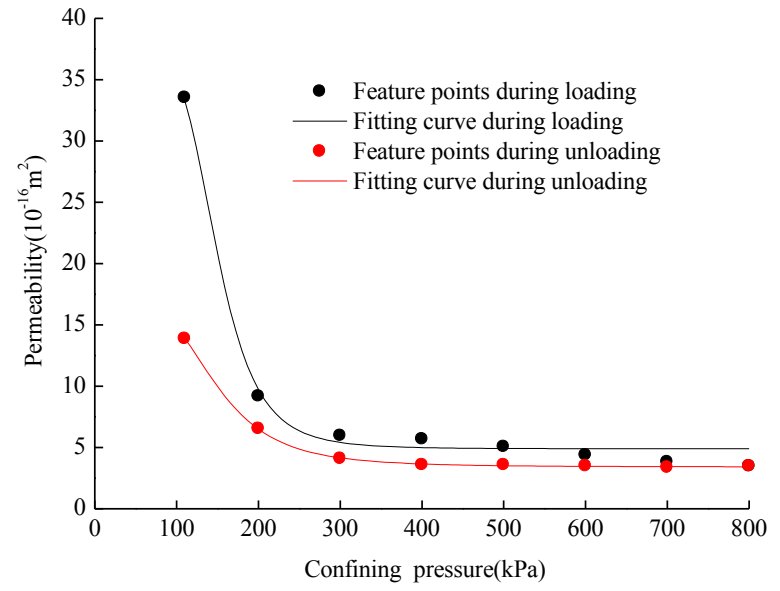

(a) Sandstone sample A1-1

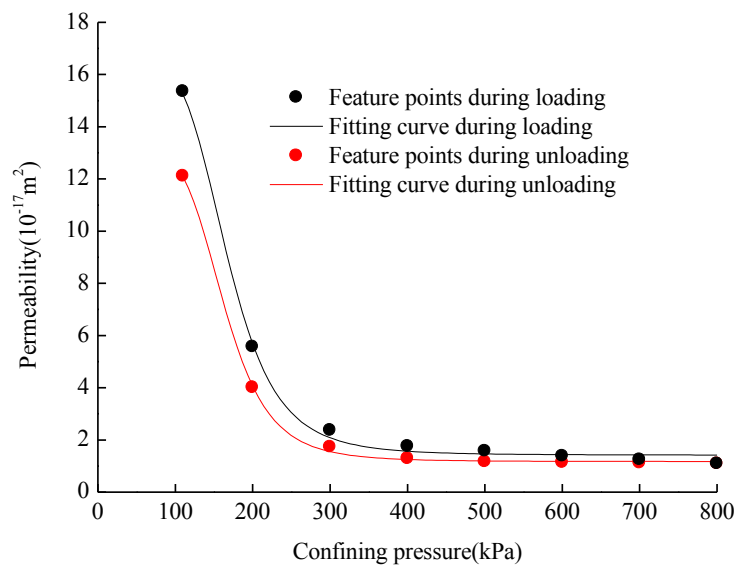

(b) Sandstone sample A2-3

Fig. 4. Fitting curves of relations between permeability and confining pressure

\begin{tabular}{|c|c|c|c|c|c|}
\hline $\begin{array}{c}\text { Sandstone } \\
\text { Sample } \\
\text { Number }\end{array}$ & $\begin{array}{c}\text { Ways of } \\
\text { Loading and } \\
\text { Unloading }\end{array}$ & $a$ & $\boldsymbol{b}$ & $t$ & $\mathbf{R}^{2}$ \\
\hline \multirow{2}{*}{ A1-1 } & Loading & 4.895 & 147.51 & 5.85 & 0.9786 \\
\hline & Unloading & 3.410 & 146.03 & 3.98 & 0.9997 \\
\hline \multirow{2}{*}{ A $2-3$} & Loading & 1.419 & 166.90 & 5.28 & 0.9974 \\
\hline & Unloading & 1.174 & 162.57 & 5.61 & 0.9997 \\
\hline
\end{tabular}


In addition, the test results of Case Study A show that the permeability change law when unloading is different from that at loading. Some previous research has been conducted to study permeability under the unloading condition. To analyze the permeability change law under different confining pressure unloading levels with targets, this paper defined a variable to describe the unloading behavior, the unloading quantity of the effective confining pressure (UQECP), $\xi$, namely,

$\xi=\frac{P_{e i}-P_{e}}{P_{e i}} \times 100 \%$

where $P_{e i}$ is the initial effective confining pressure, and $P_{e}$ is the effective confining pressure at certain moment. Eq. (4) shows that $\xi$ is the variable related to the pore water pressure and the confining pressure, and the change of the rock permeability under different effective confining pressures can be analyzed directly through the definition of the effective confining pressure unloading amount $\xi$. Research highlights the difference between permeability under different confining pressure unloading levels. Thus, this paper adopts the concept of permeability ratio $\left(k / k_{0}\right.$, where $k$ is the permeability under different confining pressure unloading levels, and $k_{0}$ is the permeability at the initial effective confining pressure) to correspond to the theoretical analysis of this paper.

Figure 5 shows the curves of the relations between permeability ratio $\left(k / k_{0}\right)$ during the confining pressure unloading process of the fractured sandstone and UQECP.

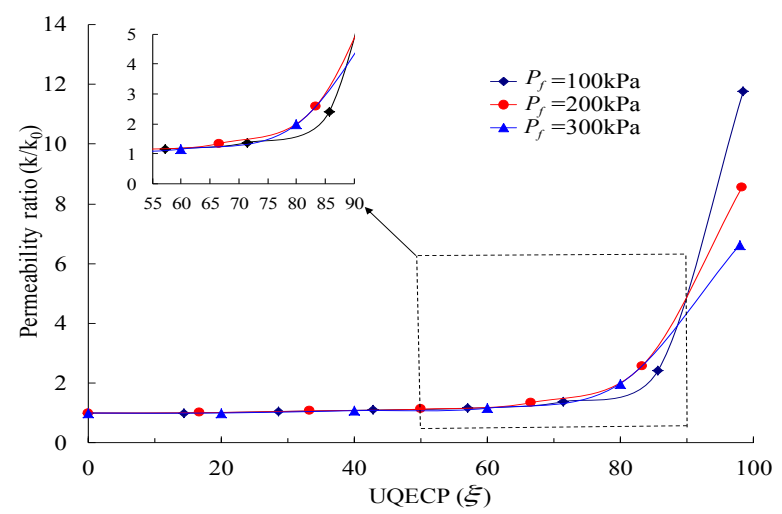

Fig. 5. Relation curves of permeability ratio and UQECP

Test results indicate that

(1) When $\xi$ is less than $60 \%$, permeability slowly increases when $\xi$ is increased under pore water pressures of 100,200 , and $300 \mathrm{kPa}$. This finding indicates that the fractures are slightly open at the initial stage of the effective confining pressure unloading, and permeability slightly changes.

(2) Figure 5 illustrates the situation when $\xi$ is between $60 \%$ and $85 \%$. When the pore water pressure is $100 \mathrm{kPa}$ and $\xi$ is $85.71 \%$, the permeability ratio is 2.42 ; when the pore water pressure is $200 \mathrm{kPa}$ and $\xi$ is $83.33 \%$, the permeability ratio is 2.58 ; when the pore water pressure is $300 \mathrm{kPa}$ and $\xi$ is $80 \%$, the permeability ratio is 1.98 . All permeability ratios increase quite rapidly or approximately twice the initial permeability ratio. Therefore, specific attention should be paid to whether the effective stress is too small, and then appropriate measures should be taken if a large increase in permeability in the construction occurs.

(3) When $\xi$ is larger than $85 \%$, the permeability ratio increases rapidly. The eventual permeability ratios are 11.78 , 8.54 , and 6.62 when the pore water pressure is 100,200 , and $300 \mathrm{kPa}$, respectively. These findings indicate that fissures and fractures within the rock gradually extend and connect with each other at this stage, forming the seepage channel and significantly increasing permeability, thereby resulting in mutability. Therefore, special attention should be paid to supporting the sandstone slope at this stage to prevent future landslides when excessively large effective confining pressure is unloaded.

(4) In general, $\xi$ describes the permeability change of the fractured sandstone. Unlike in the analysis of Case study A, $\xi$ takes the influence of the pore water pressure into consideration and may show the accelerating section and the mutation section of permeability ratio change. In the actual construction, different means of support may be adopted for the rock slope according to the initial effective confining pressure and the actually measured effective confining pressure. Meanwhile, efforts should be made to make the value of $\xi$ less than $85 \%$ to prevent any landslides caused by the excessively large permeability ratio.

\subsection{Case study $C$}

Figures 6(a) and 6(b) show relation curves of permeability ratio during the cyclic loading and unloading of the pore water pressure (where $k_{0}$ adopts permeability at the confining pressure of $800 \mathrm{kPa}$ ) when the confining pressure unloading amount is $25 \%$ (at the confining pressure of $600 \mathrm{kPa}$ ) and $50 \%$ (at the confining pressure of $400 \mathrm{kPa}$ ).

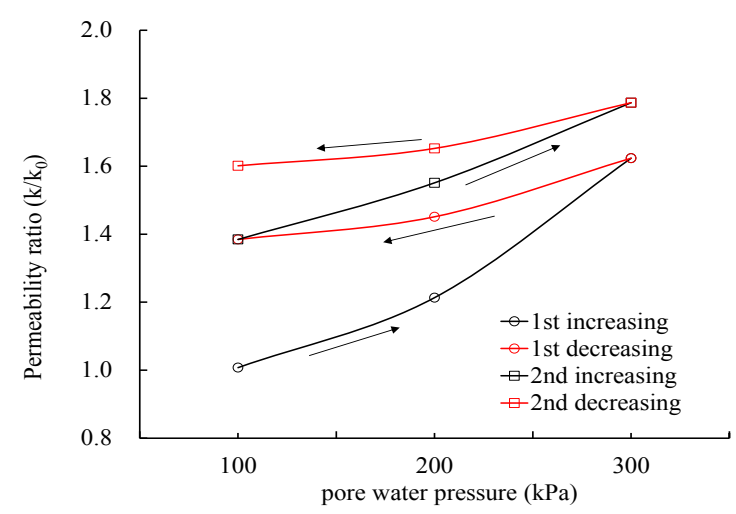

(a) Confining pressure of $600 \mathrm{kPa}$

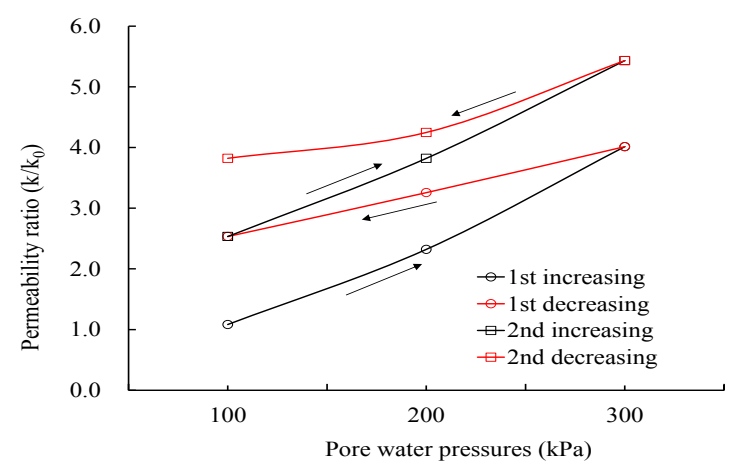

(b) Confining pressure of $400 \mathrm{kPa}$

Fig. 6. Relation curves of permeability ratio and the pore water pressure 
The following conclusion can be made from Fig. 6 :

(1) With the increase of pore water pressure, the rock blocks on both sides of the fracture surface cause more deformation, thereby increasing the crack width and permeability. When the pore water pressure is reduced, permeability does not fall along the path of the load, thereby forming a hysteresis loop. During the loading and unloading process in the pore water pressure, the sandstone is affected by the cyclic variation of the effective stress, which leads to the opening and closing of the sandstone fracture. However, the width of the final crack is now larger, thereby resulting in subtle unrecoverable plastic deformation. For the sandstone slope of the TGRR, the effect of long-term water level fluctuation on the permeability of fractured sandstone cannot be ignored.

(2) When the confining pressure is $400 \mathrm{kPa}$, permeability increases 3.5 times after two cycles of pore water pressure loading and unloading. However, when the confining pressure is $600 \mathrm{kPa}$, permeability increases 1.6 times. Therefore, the increase of confining pressure can be concluded to restrict the increase of permeability. This finding means that certain support for the bank slope considerably contributes to its stability.

The above analysis indicates that under a certain confining pressure unloading amount, the sandstone permeability is closely related to the pore water pressure. The data fitting result shows that the pore water pressure at the loading and unloading stage has high linear fitting, with the fitting curve shown in Figures 7(a) and 7(b).

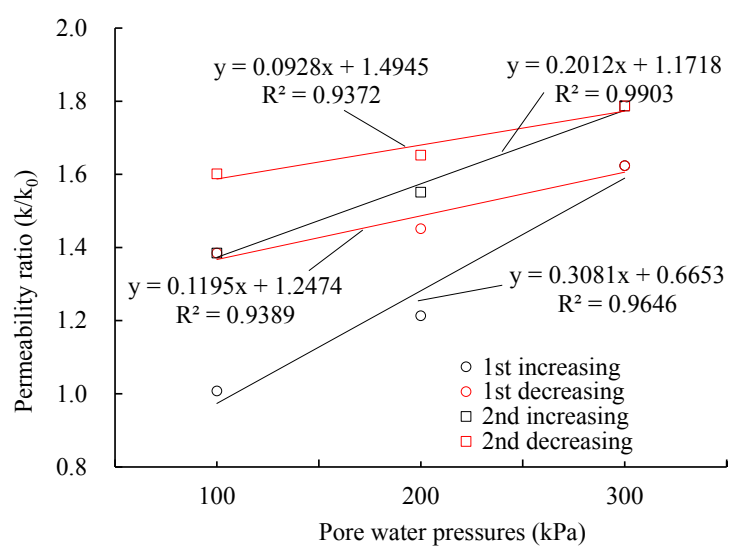

(a) Confining pressure of $600 \mathrm{kPa}$

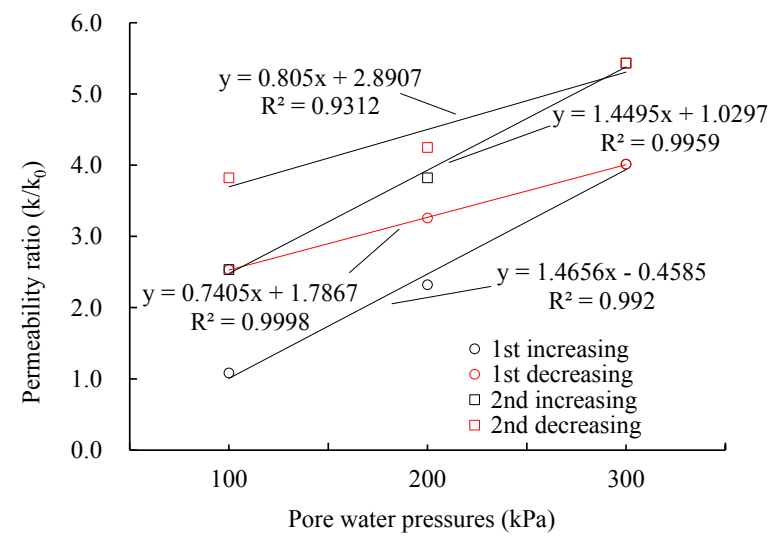

(b) Confining pressure of $400 \mathrm{kPa}$

Fig. 7. Fitting curves of permeability ratio and the pore water pressure

\subsection{Derivation of relation between permeability ratio and UQECP}

With respect to the loading process of the saturated fractured rock mass, previous research has studied the relation between the rock mass fracture and the normal stress on the rock mass, such as that of Goodman, who proposed the following relation between a single fracture surface normal stress and fracture closure:

$\sigma_{n}=\sigma_{n i}+R \sigma_{n i}\left(\frac{\Delta b}{\Delta b_{\max }-\Delta b}\right)^{t}$

where $\sigma_{n}$ is the normal stress of the fracture surface; $\sigma_{n i}$ is the initial normal stress of the fracture surface; $\Delta b$ is the closure of the fracture aperture; $\Delta b_{\max }$ is the maximum closure of the fracture aperture; and $R, t$ are test parameters.

The unloading process of the fractured sandstone of the rock slope is relatively similar to the stress release caused by the engineering excavation. Previous efforts have been directed to the loading process of the fractured sandstone, but less attention has been given to the unloading process of the saturated fractured sandstone. An equation that expresses the relation between the unloading amount and the fracture opening amount of the test piece during the unloading process is established by using the method similar to that used to simulate the loading process. As the fracture opening amount increases during the unloading process, the following equation can be obtained:

$\sigma_{n}=\sigma_{n i}-\varphi \sigma_{n i}\left(\frac{\Delta b}{b_{i n i}+\Delta b}\right)^{\eta}$

where $\sigma_{n}$ is the normal effective stress at a certain moment; $\sigma_{n i}$ is the initial normal effective stress of the fractured surface; $\Delta b$ is the closure of the fracture aperture; $b_{i n i}$ is the fracture aperture under the initial stress of $\sigma_{n i}$; and $\varphi, \eta$ are test parameters.

Through transformation, a relationship exists as follows:

$\frac{\sigma_{n i}-\sigma_{n}}{\sigma_{n i}}=\varphi\left(\frac{\Delta b}{b_{i n i}+\Delta b}\right)^{\eta}$

$\xi$ is defined as $\xi=\frac{\sigma_{n i}-\sigma_{n}}{\sigma_{n i}}$. As the fracture is formed in the test with the uniaxial loading in the axial direction, main fractures are vertical when the value of $\xi$ is equal to the value of the effective confining pressure unloading amount. Therefore, the above equation can be simplified as follows:

$$
\xi=\varphi\left(\frac{\Delta b}{b_{\text {ini }}+\Delta b}\right)^{\eta}
$$

When Eq. (10) is transformed, the following equation can be obtained: 


$$
\Delta b=\frac{(\xi / \varphi)^{\frac{1}{\eta}} b_{i n i}}{1-(\xi / \varphi)^{\frac{1}{\eta}}}
$$

Snow [20] conducted a hydraulic test on the fracture formed by two parallel plates and discovered that the flow through the fracture is directly proportional to the third power of the fracture aperture. He also found that the change of the permeability coefficient is mainly caused by the fracture aperture. Therefore, the initial permeability coefficient and fracture aperture of rock mass are assumed to be $K_{0}$ and $b_{0}$, respectively. According to the law of cube,

$K_{0}=\frac{g b_{0}^{3}}{12 v s}$

where $g$ is the acceleration of gravity; $v$ is the kinematic viscosity coefficient of water; and $s$ is the fracture distance.

Thus, permeability coefficient $K$ at any moment is

$K=\frac{g\left(b_{0}+\Delta b\right)^{3}}{12 v s}$

This paper adopts water as the medium to test permeability. Thus, the relation between permeability and permeability coefficient can be expressed as

$k=\frac{\mu K}{\gamma}=\frac{v K}{g}$

where $k$ is the permeability; $K$ is the permeability coefficient; $\mu$ is the viscosity of water; $\gamma$ is the volume weight of water; $v$ is the kinematic viscosity coefficient of water; and $g$ is the acceleration of gravity.

Thus,

$\frac{k}{k_{0}}=\frac{g\left(b_{0}+\Delta b\right)^{3}}{12 v s} / \frac{g b_{0}^{3}}{12 v s}=\left(1+\frac{\Delta b}{b_{0}}\right)^{3}$

According to Eqs. (11) and (15),

$\frac{k}{k_{0}}=\left(1+\frac{(\xi / \varphi)^{\frac{1}{\eta}}}{1-(\xi / \varphi)^{\frac{1}{\eta}}}\right)^{3}=\frac{1}{\left(1-(\xi / \varphi)^{\frac{1}{\eta}}\right)^{3}}$

According to Eq. (16), with the use of the data in Scheme II, the relation between the permeability ratio and the effective confining pressure unloading amount is fitted with the original self-defining function, as shown in Figure 8 Regression parameters including $\varphi, \eta$, and $\mathrm{R}^{2}$ are shown in Table 3. The expression calculated and obtained from Eq. (16) is preferably fitted with the test data, which means the derived equation describes the relationship between permeability and the confining pressure unloading amount under different pore water pressures unloading conditions. Scheme II considers the function of both the pore water pressure and the confining pressure; thus, it can relatively truly reflect the stress condition of fractured sandstone slopes in the TGRR. Therefore, the accelerated growth and mutation area of permeability of the fractured sandstone may be predicted according to field measurement data, thereby contributing significantly to the control of landslides in the TGRR.

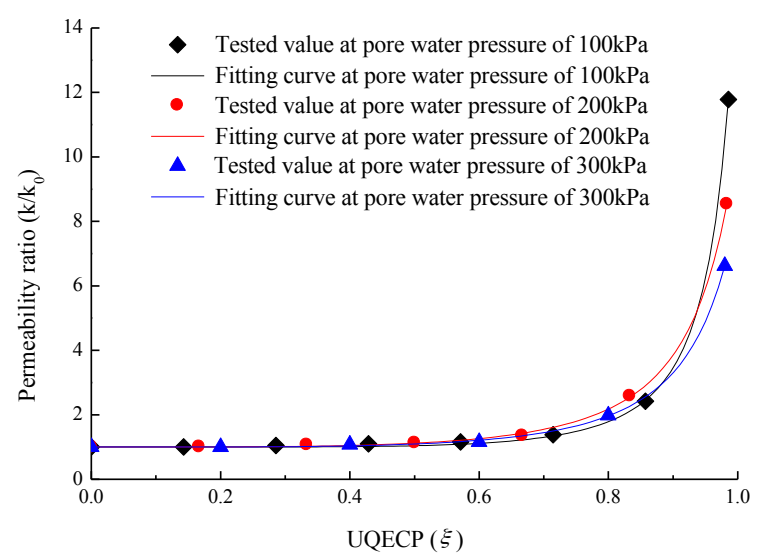

Fig. 8. Fitting curves of permeability ratio and UQECP

Table 3. Fitting parameters and $\mathrm{R}^{2}$

\begin{tabular}{c|l|l|l}
\hline $\begin{array}{c}\text { Pore water } \\
\text { pressure }\end{array}$ & $\varphi$ & $\eta$ & $\mathbf{R}^{2}$ \\
\hline $100 \mathrm{kPa}$ & 1.0941 & 0.1802 & 0.9998 \\
$200 \mathrm{kPa}$ & 1.1682 & 0.2565 & 0.9997 \\
$300 \mathrm{kPa}$ & 1.1777 & 0.2415 & 0.9998 \\
\hline
\end{tabular}

\section{Conclusions}

To study the law of permeability of the rock slope, permeability characteristic tests were conducted on sandstone from the TGRR under loading and unloading conditions. Then, the change of permeability was studied through curve fitting and theoretical analysis. The following conclusions were obtained:

(1) The permeability of the fractured sandstone is approximately 20 times that of the intact sandstone under the same confining pressure. The permeability characteristics of sandstone slope are controlled by the fractured sandstone. In addition, the relationship between the sandstone permeability and the confining pressure during loading and unloading conformed with the change law of Eq. (2), which predicts the mutation area of permeability. Therefore, this study is of significance for engineering.

(2) Special attention should be paid to supporting the sandstone slope when $\xi$ is larger than $85 \%$ to prevent future landslides. According to the expression of permeability ratio and the effective confining pressure unloading amount under unloading condition, the accelerated growth and the mutation area of permeability of the fractured sandstone can be predicted, which is significant to the control of landslides in the TGRR.

(3) Permeability ratio presented a linear relation with the loading and unloading of the pore water pressure. Generally, the permeability increased with the increase of pore water pressure. When the pore water pressure decreased, the permeability did not fall along the path of the load, thereby forming subtle unrecoverable plastic deformation. Thus, the influence of water level fluctuation on the permeability of fractured sandstone cannot be ignored. 
This paper carried out permeation law evolution tests on the sandstone slope under loading and unloading, which are in line with the actual situations. This study greatly contributes to research on landslides caused by water in the TGRR. However, the permeability of rock slope under longterm cycle of water level variation in the TGRR has not been addressed adequately. Thus, further study is needed.

\section{Acknowledgments}

This study was supported by Scientific Research Foundation of State Key Lab. of Coal Mine Disaster Dynamics and Control(Project no. 2011DA105287-MS201208), the Fundamental Research Funds for Central Universities of China (Project no. CDJXS12201106) and the Natural Science Foundation of Chongqing, China (Project no. cstc2013jcyjA30005).

\section{References}

1. F. W. Wang, Y. M. Zhang, Z. T. Huo, T. Matsumoto, and B. L. Huang, "The July 14, 2003 Qianjiangping landslide, Three Gorges Reservoir, China", Landslides, 1(2), 2004, pp. 157-162.

2. W. Jian, Z. Wang, and K. Yin, "Mechanism of the Anlesi landslide in the Three Gorges Reservoir, China", Engineering Geology, 108(1-2), 2009, pp. 86-95.

3. S. B. Bai, J. Wang, G. N. Lü, P. G. Zhou, S. S. Hou, and S. N. Xu, "GIS-based logistic regression for landslide susceptibility mapping of the Zhongxian segment in the Three Gorges area, China", Geomorphology, 115(1-2), 2010, pp. 23-31.

4. M. Xia, G. M. Ren, and X. L. Ma, "Deformation and mechanism of landslide influenced by the effects of reservoir water and rainfall, Three Gorges, China", Natural Hazards, 68(2), 2013, pp. 467-482.

5. L. Peng, R. Niu, B. Huang, X. Wu, Y. Zhao, and R. Ye, "Landslide susceptibility mapping based on rough set theory and support vector machines: A case of the Three Gorges area, China", Geomorphology, 204(1), 2014, pp. 287-301.

6. X. L. Hu, H. M. Tang, C. D. Li, and R. X. Sun, "Stability of Huangtupo riverside slumping mass II\# under water level fluctuation of Three Gorges Reservoir", Journal of Earth Science, 23(3), 2012, pp. 326-334.

7. T. T. Zhang, E. C. Yan, J. T. Cheng, and Y. Zheng, "Mechanism of reservoir water in the deformation of Hefeng landslide", Journal of Earth Science, 21(6), 2012, pp. 870-875.

8. A. Baghbanan, and L. Jing, "Stress effects on permeability in a fractured rock mass with correlated fracture length and aperture", International Journal of Rock Mechanics \& Mining Sciences, 45(8), 2008, pp. 1320-1334.

9. J. He, S. H. Chen, and I. Shahrour, "Numerical estimation and prediction of stress-dependent permeability tensor for fractured rock masses", International Journal of Rock Mechanics \& Mining Sciences, 59(5), 2013, pp. 70-79.

10. Z. Zhao, L. Jing, I. Neretnieks, and L. Moreno, "Numerical modeling of stress effects on solute transport in fractured rocks", Computers and Geotechnics, 38(2), 2011, pp. 113-126.
11. G. Yin, W. Li, C. Jiang, M. Li, X. Li, H. Liu, and Q. Zhang, "Mechanical property and permeability of raw coal containing methane under unloading confining pressure", International Journal of Mining Science and Technology, 23(6), 2013, pp. 789793.

12. W. Al-Wardy, and R. W. Zimmerman, "Effective stress law for the permeability of clay-rich sandstones", Journal of Geophysical Research Atmospheres, 109(B4), 2004, pp. 229-245.

13. O. Kwon , A. K. Kronenberg, A. F. Gangi, and B. Johnson, "Permeability of Wilcox shale and its effective stress law", Journal of Geophysical Research Atmospheres, 106(B9), 2001, pp. 1933919353.

14. J. Sun, and Z. Zhao, "Effects of anisotropic permeability of fractured rock masses on underground oil storage caverns", Tunnelling and Underground Space Technology, 25(5), 2010, pp. 629-637.

15. X. Zhang, and D. J. Sanderson, "Anisotropic features of geometry and permeability in fractured rock masses", Engineering Geology, 40(40), 1995, pp. 65-75.

16. J. Rutqvist, "Fractured rock stress-permeability relationships from in situ data and effects of temperature and chemical-mechanical couplings", Geofluids, 15(1-2), 2014, pp. 48-66.

17. S. Chi, S. Ni, and Z. Liu, "Back Analysis of the Permeability Coefficient of a High Core Rockfill Dam Based on a RBF Neural Network Optimized Using the PSO Algorithm", Mathematical Problems in Engineering, 2015(118), 2005, pp. 1-15.

18. C. T. O. Leung, and R. W. Zimmerman, "Estimating the Hydraulic Conductivity of Two-Dimensional Fracture Networks Using Network Geometric Properties", Transport in Porous Media, 93(3), 2012, pp. 777-797.

19. M. A. Biot, "General theory of three-dimensional consolidation", Journal of Applied Physics, 12(2), 1941, pp. 155-164.

20. D. T. Snow, "Anisotropic permeability of fractured media," Water Resources Research, 5(6), 1969, pp. 1273-1289. 